\title{
Identifying and ranking the factors affecting entrepreneurial marketing to facilitate exports
}

\author{
Mehdi Habibzadeh*, Fattaneh Alizadeh Meshkani and Abdolhamid Hajipoor Shoshtari
}

Department of Management and Accounting, South Tehran Branch, Islamic Azad University, Tehran, Iran

\begin{tabular}{l} 
C H R O N I C L E \\
\hline Article history: \\
Received October 28, 2015 \\
Received in revised format \\
November 28, 2015 \\
Accepted January 25, 2016 \\
Available online \\
January 25, 2016 \\
\hline Keywords: \\
SMEs \\
Export \\
Entrepreneurial marketing
\end{tabular}
\begin{abstract}
A B S T R A C T
Small and medium enterprises (SMEs) are believed the most important components of today's businesses and they can boost the growth of economy. This paper presents an empirical investigation to identify and rank important factors influencing on entrepreneurial marketing to facilitate exports of SMEs. The study designs a questionnaire in Likert scale and distributes it among 387 randomly selected entrepreneurs who act as managers of some SMEs in city of Tehran, Iran. Cronbach alpha is calculated as 0.873 , which is well above the acceptable level. Using principle component analysis, the study has determined four factors including competitive intelligence, competitive advantage, external factors and internal factors to facilitate the export of SMEs.
\end{abstract}

\section{Introduction}

During the last few years, there have been extensive efforts on detecting important factors for stimulating small and medium enterprises (SMEs) (Nikfarjam \& Zarifi, 2015). Knight (2000) investigated the interrelationships of entrepreneurial orientation, marketing strategy, tactics, and organization performance among SMEs influenced by globalization. Oparaocha (2015) investigated the effect of the applying of institutional networks by SMEs in the context of international entrepreneurship (IE). The study shed light into SMEs' awareness of, reaching to, and actual implementation of the resources available through institutional networks and whether these were inducements or deterrents for entrepreneurial activities in foreign markets. A qualitative study design using a multiple case study method was implemented to examine five internationalized SMEs from Sweden and Finland. The results recommended that institutional network relationships had a positive impact on the internationalization process of SMEs. Nevertheless, the effect was continuous and intertwined in various stages of the internationalization process.

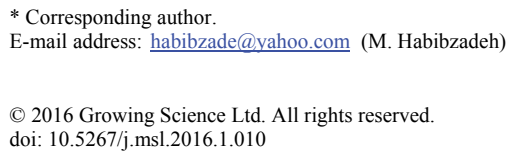


Öztamur and Karakadilar (2014) explored the role of social media for SMEs as a new marketing strategy tool for the firm performance perspective. They concentrated on a case study incorporating the comparison and analysis of totally four American and Turkish companies' Facebook and Twitter accounts according to the number of likes and followers, richness of content, interaction with customers and the use of language. They reported that the common problems of the Turkish SMEs were associated with using formal language during the customers' communication process and generating unattractive content lacking richness to absorb their customers' attention in their social media activities.

According to Zaridis and Mousiolis (2014), theories developed about Entrepreneur and SME highlight the relative importance of certain factors like "business size, market share, management and ownership, data associated with the survival and competitiveness of SMEs, potential fundraising, sales, profitability and liquidity, lack of skilled personnel in the industry, distribution channels data and market information, barriers to entry in certain markets, changes taking place in markets, birth of niche markets, operation in a niche, closed or protected local or regional market, data on acquisition of a business, use of innovation or new technologies, organizational structure, customers, suppliers, creditors and relationship with public institutions and policies, lack of confidence in external consultants, resources control, networking and clustering".

Tzoulis et al. (2013) explained the implementation of some modern marketing tool, a database named as WooDB in SMEs. Zehir et al. (2015) studied the relationship between market orientation, innovation capability and export performance as well as the mediator effect of innovation ability on the relationship between market orientation and export performance with an implementation on SMEs in Turkey. They reported that innovation capability had a partial mediator impact on market orientation dimensions and export performance. The results indicated that SMEs could be able to reach competitive advantage through improving a market-driven innovation capability. Tsai and Kuo (2011) proposed an integrated model to address the constraints of itemized annual budgets in an empirical case study of entrepreneurship policy for SMEs in Taiwan. The results indicated that incubator center, financial assistance, and knowledge-sharing platforms could help policy makers evaluate and select feasible entrepreneurship policy mix.

\section{The proposed study}

Small and medium enterprises (SMEs) are believed the most important components of today's businesses and they can boost the growth of economy. This paper presents an empirical investigation to identify and rank important factors influencing on entrepreneurial marketing to facilitate exports of SMEs. The study has accomplished among the managers of SMEs who were active in city of Tehran, Iran. The sample size is calculated as follows,

$$
N=Z_{\alpha / 2}^{2} \frac{p \times q}{e^{2}},
$$

where $N$ is the sample size, $p=1-q$ represents the probability, $z_{\alpha / 2}$ is CDF of normal distribution and finally $\varepsilon$ is the error term. For our study we assume $p=0.5, z_{\alpha / 2}=1.96$ and $e=0.05$, the number of sample size is calculated as $N=384$. The study designs a questionnaire in Likert scale and distributes it among 387 randomly selected entrepreneurs who act as managers of some SMEs in city of Tehran, Iran. Cronbach alpha is calculated as 0.873 , which is well above the acceptable level. In addition, KaiserMeyer-Olkin Measure of Sampling Adequacy yields a Chi-Square value of 3142.45 with Sig. $=0.000$. Table 1 shows the results of Communalities. As we can observe from Table 1, all values are greater than 0.5 and these variables are used for the implementation of principle component analysis. Table 2 shows the results of our findings. Fig. 1 also shows the results of Scree plot. 
Table 1

The summary of Communalities

\begin{tabular}{lccccc}
\hline & Initial & Extraction & & Initial & Extraction \\
\hline VAR00002 & 1.000 & .560 & VAR00016 & 1.000 & .661 \\
VAR00003 & 1.000 & .553 & VAR00018 & 1.000 & .546 \\
VAR00004 & 1.000 & .559 & VAR00019 & 1.000 & .598 \\
VAR00007 & 1.000 & .833 & VAR00020 & 1.000 & .533 \\
VAR00008 & 1.000 & .954 & VAR00021 & 1.000 & .833 \\
VAR00009 & 1.000 & .955 & VAR00022 & 1.000 & .954 \\
VAR00010 & 1.000 & .935 & VAR00023 & 1.000 & .955 \\
VAR00011 & 1.000 & .726 & VAR00024 & 1.000 & .935 \\
VAR00012 & 1.000 & .980 & VAR00025 & 1.000 & .726 \\
VAR00013 & 1.000 & .805 & VAR00026 & 1.000 & .980 \\
VAR00014 & 1.000 & .966 & VAR00027 & 1.000 & .805 \\
VAR00015 & 1.000 & .585 & VAR00028 & 1.000 & .966 \\
\hline
\end{tabular}

Table 2

The summary of principle component analysis

\begin{tabular}{|c|c|c|c|c|c|c|c|c|c|}
\hline \multirow[t]{2}{*}{ Component } & \multicolumn{3}{|c|}{ Initial Eigenvalues } & \multicolumn{3}{|c|}{ Extraction Sums of Squared Loadings } & \multicolumn{3}{|c|}{ Rotation Sums of Squared Loadings } \\
\hline & Total & $\%$ of Variance & Cumulative \% & Total & $\%$ of Variance & Cumulative \% & Total & $\%$ of Variance & Cumulative $\%$ \\
\hline 1 & 5.608 & 23.366 & 23.366 & 5.608 & 23.366 & 23.366 & 3.148 & 13.117 & 13.117 \\
\hline 2 & 3.534 & 14.725 & 38.092 & 3.534 & 14.725 & 38.092 & 2.456 & 10.235 & 23.352 \\
\hline 3 & 2.487 & 10.364 & 48.455 & 2.487 & 10.364 & 48.455 & 2.361 & 9.836 & 33.188 \\
\hline 4 & 1.882 & 7.843 & 56.298 & 1.882 & 7.843 & 56.298 & 2.279 & 9.494 & 42.682 \\
\hline 5 & 1.802 & 7.510 & 63.808 & 1.802 & 7.510 & 63.808 & 2.269 & 9.454 & 52.136 \\
\hline 6 & 1.349 & 5.620 & 69.428 & 1.349 & 5.620 & 69.428 & 2.196 & 9.151 & 61.287 \\
\hline 7 & 1.182 & 4.925 & 74.353 & 1.182 & 4.925 & 74.353 & 2.110 & 8.792 & 70.079 \\
\hline 8 & 1.060 & 4.418 & 78.772 & 1.060 & 4.418 & 78.772 & 2.086 & 8.693 & 78.772 \\
\hline 9 & .992 & 4.135 & 82.907 & & & & & & \\
\hline 10 & .888 & 3.700 & 86.607 & & & & & & \\
\hline 11 & .728 & 3.034 & 89.641 & & & & & & \\
\hline 12 & .595 & 2.481 & 92.122 & & & & & & \\
\hline 13 & .555 & 2.313 & 94.434 & & & & & & \\
\hline 14 & .496 & 2.068 & 96.502 & & & & & & \\
\hline 15 & .491 & 2.046 & 98.548 & & & & & & \\
\hline 16 & .348 & 1.452 & 100.000 & & & & & & \\
\hline 17 & $1.751 \mathrm{E}-016$ & 7.297E-016 & 100.000 & & & & & & \\
\hline 18 & $9.698 \mathrm{E}-017$ & 4.041E-016 & 100.000 & & & & & & \\
\hline 19 & 1.404E-017 & $5.850 \mathrm{E}-017$ & 100.000 & & & & & & \\
\hline 20 & $-2.617 \mathrm{E}-017$ & $-1.091 \mathrm{E}-016$ & 100.000 & & & & & & \\
\hline 21 & $-3.059 \mathrm{E}-017$ & $-1.274 \mathrm{E}-016$ & 100.000 & & & & & & \\
\hline 22 & $-7.398 \mathrm{E}-017$ & $-3.082 \mathrm{E}-016$ & 100.000 & & & & & & \\
\hline 23 & $-1.069 \mathrm{E}-016$ & $-4.456 \mathrm{E}-016$ & 100.000 & & & & & & \\
\hline 24 & $-2.703 \mathrm{E}-016$ & $-1.126 \mathrm{E}-015$ & 100.000 & & & & & & \\
\hline
\end{tabular}

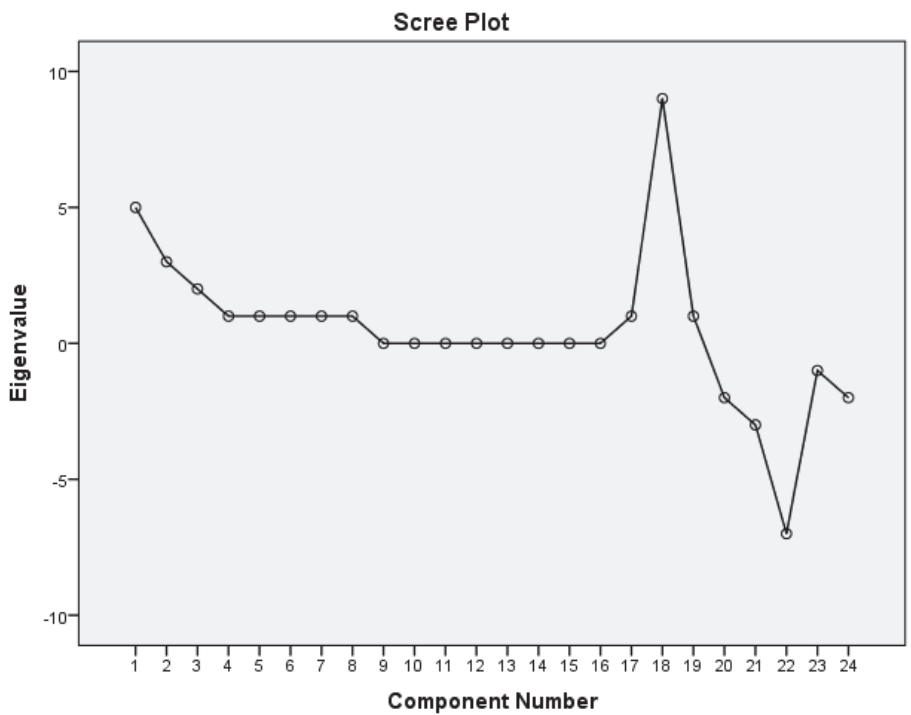

Fig. 1. The results of Scree plot 
Table 3

The results of principle component analysis using Varimax rotation

\begin{tabular}{|c|c|c|c|c|c|c|c|c|}
\hline & 1 & 2 & 3 & 4 & 5 & 6 & 7 & 8 \\
\hline Know-how of employee & .388 & & & & & .616 & & \\
\hline Product diversification & & & & & & .667 & & \\
\hline Firm age & & & & & & .675 & & \\
\hline Geographical distance & & .485 & & .389 & & .553 & & \\
\hline foreign markets information & & .943 & & & & & & \\
\hline Distribution network & & & & .959 & & & & \\
\hline Legal requirement & & & .914 & & & & & \\
\hline Product quality & .593 & & .465 & & & & & \\
\hline Increasing the number of new markets & & & & & & & & .969 \\
\hline Export experience & .858 & & & & & & & \\
\hline Entry mode to foreign markets & & & & & & & .956 & \\
\hline Cooperate with other firms ( especially across borders & -.383 & & & & .543 & & & \\
\hline Bribery and favouritism & -.523 & & & & .509 & & & \\
\hline Technology transfer & & & & & .669 & & & \\
\hline Economic and political stability & & & & & .733 & & & \\
\hline Tax system & & & & & .680 & & & \\
\hline Transportation problem & & .485 & & .389 & & .553 & & \\
\hline Creativity & & .943 & & & & & & \\
\hline Leadership & & & & .959 & & & & \\
\hline Specification & & & .914 & & & & & \\
\hline Bureaucracy & .593 & & .465 & & & & & \\
\hline Access to insurance and alliances & & & & & & & & .969 \\
\hline Access to market rules & .858 & & & & & & & \\
\hline Government policy & & & & & & & .956 & \\
\hline
\end{tabular}

\section{Conclusion and discussion}

According to the results of Fig 2, which summarizes the results of our survey, four factors including competitive intelligence, competitive advantage, external factors and internal factors are believed to be the most important factors for facilitating the export of SMEs. The first factor, competitive intelligence, consists of four factors including, creativity, employee skills, R \& D investment and foreign market information. The second factor, competitive advantage, includes product diversification, marketing methods and access to infrastructures. The third factor, external factors, includes five factors including market investment, cooperation with other firms, technology transfer, government policy and financial support. Finally, the last factor, internal factors, includes three items including product quality, product diversification and firm innovation. The results of this survey are consistent with findings of other studies.

Nikfarjam and Zarifi (2015), for instance, performed an exploration investigation to determine entrepreneurial marketing factors influencing on SMEs, which were active in Iranian food industry. They reported that five factors including innovative approach, flexible marketing, customer, product strategy and resources were influencing the most on entrepreneurial marketing factors. Alibeyki and Khosravi (2014) performed a study for strategic knowledge management assessment of SMEs based on value creation and opportunities abduction. Mahroeian (2012) performed a survey on the effect of different factors on e-Commerce adoption among SMEs of Malaysia and demonstrated that ecommerce adoption had been significantly influenced by its organizational readiness, perceived ease of use, and also perceived usefulness factors. 


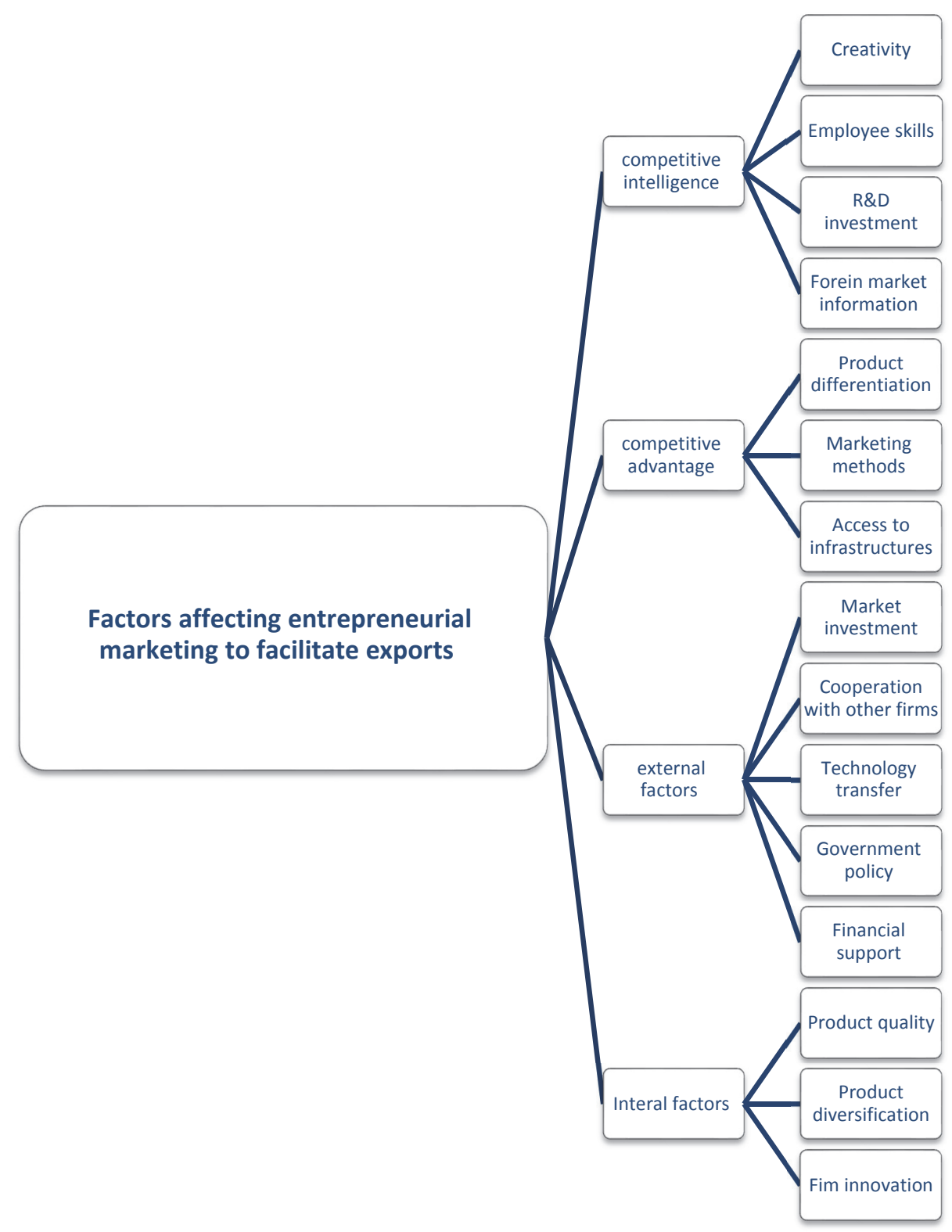

Fig. 2. The results of principle component analysis

\section{Acknowledgement}

The authors would like to thank the anonymous referees for constructive comments on earlier version of this paper.

\section{References}

Alibeyki, B \& Khosravi, M. (2014). Strategic knowledge management assessment of SMEs based on value creation and opportunities abduction. Management Science Letters, 4(7), 1511-1518.

Knight, G. (2000). Entrepreneurship and marketing strategy: The SME under globalization. Journal of International Marketing, 8(2), 12-32.

Mahroeian, H. (2012). A study on the effect of different factors on e-Commerce adoption among SMEs of Malaysia. Management Science Letters, 2(7), 2679-2688. 
Nikfarjam, A., \& Zarifi, S. (2015). Exploring the effects of entrepreneurial marketing factors on SMEs. Uncertain Supply Chain Management, 3(4), 333-338.

Oparaocha, G. O. (2015). SMEs and international entrepreneurship: An institutional network perspective. International Business Review. 24(5), 861-873.

Öztamur, D., \& Karakadılar, İ. S. (2014). Exploring the role of social media for SMEs: As a new marketing strategy tool for the firm performance perspective. Procedia-Social and Behavioral Sciences, 150, 511-520.

Tsai, W. H., \& Kuo, H. C. (2011). Entrepreneurship policy evaluation and decision analysis for SMEs. Expert Systems with Applications, 38(7), 8343-8351.

Tzoulis, I., Andreopoulou, Z., Koliouska, C., Tsekouropoulos, G., \& Samathrakis, V. (2013). WooDB: a DBMS approach as a marketing tool for wood entrepreneurship. Procedia Technology, 8, 275284.

Zehir, C., Köle, M., \& Yıldız, H. (2015). The mediating role of innovation capability on market orientation and export performance: An implementation on SMEs in Turkey. Procedia-Social and Behavioral Sciences, 207, 700-708.

Zaridis, A. D., \& Mousiolis, D. T. (2014). Entrepreneurship and SME's organizational structure. Elements of a successful business. Procedia-Social and Behavioral Sciences, 148, 463-467.

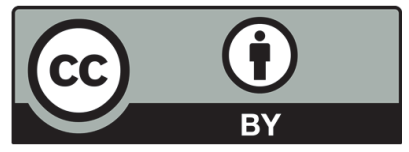

(C) 2016 by the authors; licensee Growing Science, Canada. This article is an open access article distributed under the terms and conditions of the Creative Commons Attribution (CC-BY) license (http://creativecommons.org/licenses/by/4.0/). 